\title{
Diversity in Drought Traits among Commercial Southeastern US Peanut Cultivars
}

\author{
Mura Jyostna Devi and Thomas R. Sinclair \\ Crop Science Department, North Carolina State University, Raleigh, NC 27695, USA \\ Correspondence should be addressed to Thomas R. Sinclair, trsincla@ncsu.edu
}

Received 13 August 2011; Accepted 12 September 2011

Academic Editor: David Clay

Copyright (C) 2011 M. J. Devi and T. R. Sinclair. This is an open access article distributed under the Creative Commons Attribution License, which permits unrestricted use, distribution, and reproduction in any medium, provided the original work is properly cited.

Commercial peanut cultivars in the USA are often grown under soil and environmental conditions resulting in intermittent periods of water deficit. Two plant traits have been identified that result in conservative use of water and allow sustained growth during drought: (1) restricted transpiration rate under high atmospheric vapor pressure deficit (VPD) and (2) earlier closure of stomata in the soil-drying cycle resulting in decreased daily transpiration rate. The objective of this study was to investigate whether there was diversity in these two putative traits for drought resistance among nine US commercial peanut cultivars. When the response to VPD was measured at an average temperature of $32^{\circ} \mathrm{C}$, eight of the nine cultivars expressed a restricted transpiration rate at high VPD. However, at $24^{\circ} \mathrm{C}$ none of the cultivars exhibited a restriction of transpiration rate at high VPD. No differences were found among the nine cultivars in their response to soil drying.

\section{Introduction}

Peanut (Arachis hypogaea L.) is often grown under rainfed conditions on soils with limited water-holding capacity. Hence, an ability to sustain development and growth under water deficit is important for commercial cultivars. While studies have examined traits to enhance peanut performance under water-limited conditions, there is no report specifically on genetic variability among cultivars used commercially in southeast USA. This study was designed to examine specific drought-tolerant traits in nine commercial peanut cultivars.

One putative drought-tolerant trait is to limit transpiration rate by having a decreased stomatal conductance under conditions when atmospheric vapor pressure deficit (VPD) is high $[1,2]$. Without sensitivity to increasing VPD, plants will have continually increasing transpiration rates with increasing VPD [3]. One possibility, however, is for plants to limit transpiration to a maximum rate when VPD becomes high. Such behavior is observed as midday stomata closure. This trait has the benefit of conserving soil water during periods of high VPD so that it might be available for use later in the season if soil water deficits develop. Such a response of transpiration to VPD has been previously identified in some genotypes of soybean (Glycine max (Merr.) L.) [46], sorghum (Sorghum biocolor L.) [7], and pearl millet (Pennisetum glaucum (L.) R.Br) [8].

A sensitivity of transpiration to VPD has also been recently reported in peanut. Jyostna Devi et al. [9] studied seventeen peanut breeding lines and commercial lines used in India. They found that nine of the lines had a breakpoint in the transpiration rate with increasing VPD at about $2 \mathrm{kPa}$. Above the breakpoint, there was little or no further increase in transpiration rate. The lines expressing a breakpoint were proposed as good candidates for use in developing peanut lines for drought conditions in India. However, none of these lines are used commercially in the USA.

A second putative trait to confer drought tolerance involves the response of transpiration rate to soil drying. In general, transpiration rate is unaffected by soil drying until the soil dries to a volumetric water content where the rate of water uptake from the soil requires that transpiration rate be limited [10]. Sinclair and Ludlow [11] examined the response to soil drying by expressing soil water content as fraction of transpirable soil water (FTSW). The FTSW variable has been successfully used to define transpiration response to soil drying in many plant species [11-16]. The threshold for the 
decline in transpiration rate commonly occurs when FTSW declines to the range of 0.3 to 0.4 [11-13, 17-22].

The response of transpiration to soil drying has also been studied among peanut genotypes. Jyostna Devi et al. [23] also examined the seventeen genotypes from India for possible variation in their response to drying soil. Instead of a fairly constant value across genotypes, the FTSW threshold for initiation of the decline in transpiration rate ranged from 0.22 to 0.71 among these genotypes. Jyostna Devi et al. [23] hypothesized that the genotypes with a high FTSW threshold were more suitable for water-deficit conditions because stomata closure at high soil water content allowed for water conservation early in the soil drying cycle. Again, none of these genotypes are used commercially in the USA.

Although Jyostna Devi et al. [9, 23] identified substantial genetic variation for the two putative traits for enhancing crop performance under water-limited conditions, it is unknown whether such variation exists in commercial cultivars grown in the USA. Do US commercial cultivars express differences in these two traits that might be advantageous in water-limited conditions, or have these traits not yet been exploited to increase the drought resistance of commercial cultivars? Therefore, the objective of this study was to compare the expression of the VPD response and soil drying response of nine commercial peanut cultivars grown in the USA.

\section{Materials and Methods}

Peanut material used in the following study was commercial varieties obtained from USDA, Agricultural Experimental Research Station, Dawson, Georgia. The nine cultivars used in this study are listed in Table 1.

2.1. Transpiration Response to VPD. Transpiration response of individual peanut plants in response to various atmospheric VPD was measured in the same chamber system described by Jyostna Devi et al. [9]. In brief, plants were grown in $100 \mathrm{~mm}$ diameter $\times 180 \mathrm{~mm}$ high pots made from polyvinyl chloride pipes (PVCs) and filled with garden soil (Miracle-Gro Lawn Products, Inc., Marysville, Ohio, USA). Dates for sowing the two seeds in each pot are given in Table 1. Before sowing, the seeds were inoculated with rhizobium (Southern State Cooperative, Richmond, VA, USA) using the liquid inoculation method [24]. After one week, plants were thinned to one plant per each pot. Plants were grown in a greenhouse under natural solar radiation with the air temperature regulated at $27^{\circ} \mathrm{C}$ day $/ 21^{\circ} \mathrm{C}$ night. The pots were maintained in a well-watered condition through the measurements of VPD response (Table 1).

The evening before testing the VPD response, all pots were fully watered and left to drain overnight. The following morning, the soil surface around the plant was sealed with aluminum foil to prevent soil evaporation. A $254 \mathrm{~mm}$ diameter lid of a food container (Rubbermaid Commercial Products LLC, Winchester, VA) with an opening cut out of the center for installation over the plants was attached to the toilet flange that had been attached to the top of the pot. The $5.4 \mathrm{~L}$ translucent food container was then inverted over the plant and attached to its lid to form the VPD chamber. A $12 \mathrm{~V}, 76 \mathrm{~mm}$ diameter computer box fan (Northern Tool and Equipment, Burnsville, Minn, USA) was mounted on the chamber wall to mix the air inside the chamber. A pocket humidity/temperature pen (Extech Instruments, League City, Tex, USA) was placed through a slit in the side wall of each container to record temperature and humidity.

Different humidity levels were established around the plants in the chamber by pumping air into the container using different flow rates and sources of air [9]. Transpiration rates were measured for each plant at three humidity levels. The measurements were first begun with high humidity (low VPD), then medium humidity, and finally low humidity (high VPD). The target VPD ranges for the three levels were 0.5 to $1.5 \mathrm{kPa}, 1.5$ to $2.5 \mathrm{kPa}$, and 2.5 to $4.0 \mathrm{kPa}$. The chamber was allowed to stabilize for half an hour after setting each humidity level, and then the entire pot chamber unit was weighed to obtain the initial weight. The plants were exposed for an hour to each humidity level and then reweighed to measure the final weight. Relative humidity and temperature were recorded three times during exposure at each humidity level. When measuring the weights, the air tubes were disconnected and the potchamber units were placed on a balance (Model SI-8001, Denver Instrument, Denver, Colo, USA). The transpiration for each VPD was calculated as the difference between the initial and final weights. The measurement of transpiration response to VPD was repeated on the following day to increase the amount of data obtained for each plant.

Since there were twelve VPD chambers and data were obtained for three or four replicate plants of each cultivar, it was necessary to do the measurements in batches. The cultivars were randomly assigned to a batch. The dates for the measurement of the transpiration response for each cultivar, and the range of VPD to which the plants were exposed are given in Table 1.

Two experiments were performed on the cultivars. The first experiment was a summer sowing and the plants were grown in the greenhouse for 35 to $40 \mathrm{~d}$. The second experiment used plants grown in the greenhouse during the winter, and as a result the overall average temperature in the greenhouse to which the plants were exposed was less than in the first experiment. Consequently, the plants in the second experiment developed more slowly in the second experiment than in the first experiment and the plants were allowed to grow 40 to $50 \mathrm{~d}$ before measuring their VPD responses.

Data from all plants of each genotype on the two measurement days were combined to perform a two-segment linear regression (Prism 2.01, GraphPad Software Inc., San Diego, Calif, 1996) for transpiration rate versus VPD. If the slopes of the two segments were significantly different $(P \leq 0.05)$, then the software outputted the breakpoint and the slopes of the two linear segments. If the two slopes were not significantly different, it was concluded that there was no breakpoint in the response curve and a single linear regression was used to describe the data. 
TABLE 1: Date of sowing, experimental dates, and environmental conditions during the measurements of response to vapor pressure deficit (VPD), minimum and maximum VPD, and temperature.

\begin{tabular}{|c|c|c|c|c|c|c|}
\hline \multicolumn{7}{|c|}{ High Temperature experiment } \\
\hline \multirow[t]{2}{*}{ Genotype } & \multirow[t]{2}{*}{ Date of sowing } & \multirow[t]{2}{*}{ Date of measurement } & \multicolumn{2}{|c|}{ VPD (kPa) } & \multicolumn{2}{|c|}{ Temperature $\left({ }^{\circ} \mathrm{C}\right)$} \\
\hline & & & Minimum & Maximum & Minimum & Maximum \\
\hline AP 3 & Jul 10th, 2008 & Aug 14th \& 15th, 2008 & 1.04 & 3.36 & 29 & 36 \\
\hline AT 3085 & Jul 10th, 2008 & Aug 12th \& 13th, 2008 & 0.77 & 3.27 & 28 & 34 \\
\hline C 76-16 & Jul 10th, 2008 & Aug 12th \& 13th, 2008 & 0.85 & 3.58 & 29 & 36 \\
\hline C 99R & Jul 10th, 2008 & Aug 14th \& 15th, 2008 & 1.10 & 3.27 & 29 & 35 \\
\hline FL 07 & Sep 19th, 2008 & Oct 26th \& 27th, 2008 & 1.15 & 3.32 & 29 & 35 \\
\hline GA 04S & Jul 10th, 2008 & Aug 12th \& 13th, 2008 & 0.90 & 3.29 & 28 & 34 \\
\hline GA 06G & Jul 10th, 2008 & Aug 12th \& 13th, 2008 & 0.89 & 3.08 & 29 & 35 \\
\hline Tifrunner & Sep 19th, 2008 & Oct 26th \& 27th, 2008 & 1.31 & 3.24 & 29 & 35 \\
\hline York & Jul 10th, 2008 & Aug 14th \& 15th, 2008 & 0.90 & 3.29 & 29 & 35 \\
\hline \multicolumn{7}{|c|}{ Low Temperature experiment } \\
\hline AP 3 & Jan 16th, 2009 & Feb 27th \& 28th, 2009 & 0.92 & 3.02 & 23 & 27 \\
\hline AT 3085 & Jan 16th, 2009 & Mar 2nd \& 3rd, 2009 & 0.86 & 3.06 & 22 & 27 \\
\hline C 76-16 & Jan 16th, 2009 & Mar 2nd \& 3rd, 2009 & 0.96 & 3.01 & 22 & 27 \\
\hline C 99R & Jan 16th, 2009 & Feb 27th \& 28th, 2009 & 0.85 & 3.02 & 23 & 27 \\
\hline FL 07 & Jan 20th, 2009 & Mar 6th \& 7th, 2009 & 0.85 & 3.19 & 23 & 28 \\
\hline GA 04S & Jan 16th, 2009 & Mar 2nd \& 3rd, 2009 & 0.83 & 3.21 & 23 & 28 \\
\hline GA 06G & Jan 16th, 2009 & Mar 2nd \& 3rd, 2009 & 0.82 & 3.01 & 23 & 27 \\
\hline Tifrunner & Jan 20th, 2009 & Mar 6th \& 7th, 2009 & 0.98 & 3.05 & 23 & 27 \\
\hline York & Jan 16th, 2009 & Feb 27th \& 28th, 2009 & 0.82 & 3.08 & 23 & 27 \\
\hline
\end{tabular}

2.2. Transpiration Response to Soil Drying. Two experiments were conducted to measure the FTSW threshold for decline in transpiration rate with soil drying for the same nine cultivars used in the VPD study. The plants were grown in 200-mm diameter plastic pots filled with garden soil. A total of 12 replicate pots were established for each cultivar. The seeds were inoculated with rhizobia to ensure adequate nodulation as described above. The plants were grown in a greenhouse subjected to natural solar radiation with air temperature regulated at $27^{\circ} \mathrm{C}$ day $/ 21^{\circ} \mathrm{C}$ night. The plants were grown for approximately $35 \mathrm{~d}$ under well-watered conditions. The experimental dry-down period was from 11 to 25 June 2008 for the first water-deficit experiment and from 22 April to 5 May 2009 for the second water-deficit experiment (WD2).

The plants were fully watered the evening before the experiment began. After draining overnight, the pots were enclosed in white plastic bags and sealed around the plant stem to prevent soil evaporation. A small tube was inserted along the plant stem in each plastic bag to allow rewatering of the pots. The pots were weighed after enclosing in plastic bags and this value was recorded as the initial pot weight. Thereafter, the pots were weighed every morning beginning approximately at 09:30 EST. Daily transpiration amount was calculated as the difference in weight on successive days.

Six pots were maintained in a well-watered state throughout the experiment by adding water each day to return pot weight to $100 \mathrm{~g}$ less than the initial weight. Six pots were subjected to slow soil drying. To avoid rapid imposition of stress and to homogenize the development of drought stress across replicated plants, the decrease in soil moisture of each pot was limited to a net loss of $70 \mathrm{~g}$ per day by adding water if necessary to maintain the maximum targeted water loss. The experiment was terminated when the soil water content in drought-stressed pots decreased to a level where daily transpiration rate was less than $10 \%$ of the well-watered plants [11].

The transpiration data were analyzed by the procedure previously described by Sinclair and Ludlow [11] and Ray and Sinclair [12]. To minimize the influence of large variations in daily transpiration rate across days, the daily transpiration rates of each drought-stressed pot was normalized by dividing by the average transpiration rate on that day of the well-watered plants within each cultivar to obtain a transpiration ratio (TR)

$$
\mathrm{TR}=\frac{\text { Transpiration of stressed plant }}{\text { Mean transpiration of control }}
$$

The values of TR varied among individual plants, in part because of plant size differences. To decrease plant-to-plant variations and to facilitate comparison among cultivars, a second normalization was done. This second normalization for each plant was done by dividing the daily transpiration ratio (TR) by the mean TR of that same plant during the first 3 days of the experiment when the soil still had a high water content. This ratio was identified as the normalized transpiration ratio (NTR) and its value during the wet phase of the dry-down cycle for each plant by definition was therefore centered on a value of 1.0. 
The total transpirable soil water available to the plant in each pot was calculated as the difference between the initial and final pot weight for the entire period of soil drying. The use of transpirable soil water as the basis of comparing plant response to soil drying under a range of conditions has been effectively used in a number of studies $[12,14]$. The comparison among genotypes was further facilitated by expressing the available soil water as the fraction of transpirable soil water (FTSW) for each pot in the droughtstressed treatment on each day, so that,

$$
\text { FTSW }=\frac{(\text { Daily weight }- \text { final weight })}{(\text { Initial weight }- \text { final weight })} \text {. }
$$

The relationship between NTR and FTSW was analyzed using the same software described previously in the analysis of the VPD results. This software determined the breakpoint for the two-segment linear regression model. The FTSW value of the breakpoint where the two linear segments intersected was the critical statistic for comparing cultivars.

\section{Results}

3.1. Transpiration Response to VPD. In the VPD experiments, air flow rate and air source were successfully manipulated to achieve a range of humidities in the VPD chambers. The minimum and maximum VPD obtained across all cultivars were $0.77 \mathrm{kPa}$ and $3.58 \mathrm{kPa}$, respectively (Table 1 ). In both sets of experiments, a maximum VPD of greater than $3 \mathrm{kPa}$ was achieved in measurements for all cultivars. Due to the differences in ambient temperature in the greenhouse during the two experiments, there was a difference in chamber temperatures between experiments. In the first experiment, the range of chamber temperature was $28^{\circ} \mathrm{C}$ to $36^{\circ} \mathrm{C}$, whereas in the second experiment chamber temperature ranged between $22^{\circ} \mathrm{C}$ and $28^{\circ} \mathrm{C}$. Due to the difference in the chamber temperature of the two experiments, the first experiment was labeled as a High Temperature (HT) experiment and the second experiment as a Low Temperature (LT) experiment. The average VPD chamber temperature was $32 \pm 1.6$ and $24.2 \pm 1.4^{\circ} \mathrm{C}$ in the HT and LT experiments, respectively.

The response to VPD in all cultivars was well expressed by linear regression analysis as exemplified by cultivars AP3 and C 76-16 in Figure 1. There was a distinction between experiments in whether the results were well-described by a single linear regression or a two-segment linear regression. In the summer measurements of the HT experiment, the results for eight of the nine cultivars were found to have a two-segment response with a breakpoint (BP) (Table 2). The $R^{2}$ values for the two-segment linear regression for those cultivars exhibiting a BP ranged from 0.61 to 0.94 . The VPD of the breakpoint (BP) of the eight cultivars ranged from 1.81 $\pm 0.23 \mathrm{kPa}$ for AT 3085 to $2.25 \pm 0.13 \mathrm{kPa}$ for FL 07. Based on the confidence limit of the BP, the BPs of cv. AT 3085 and C99R were significantly lower than cv. Tifrunner and FL 07. The only exception to the two-segment response in the summer measurements was the cultivar York in which the results were described by a single linear regression.

In those cultivars in the HT experiment with a BP, the slope of transpiration rate per unit leaf area above the BP was much less than the slope at VPD less than the BP (Table 2). The slope above the $\mathrm{BP}$ ranged from $-10.10 \pm$ $3.22 \mathrm{mg} \mathrm{H}_{2} \mathrm{O} \mathrm{m}^{-2} \mathrm{~s}^{-1} \mathrm{kPa}^{-1}$ for Tifrunner to $3.63 \pm 1.87 \mathrm{mg}$ $\mathrm{H}_{2} \mathrm{O} \mathrm{m}^{-2} \mathrm{~s}^{-1} \mathrm{kPa}^{-1}$ for C99R. Out of eight cultivars found to have a BP, three had positive slopes above the BP and five cultivars had negative slopes. The linear slope of York across the whole range of VPD was comparable to the slope of the other cultivars at VPD less than the BP.

The results for the LT experiment were quite different from those of the HT experiment. In the LT experiment, all cultivars were described by a single linear regression over the entire range of VPD (Table 3 ). The linear regression described well the transpiration response with $R^{2}$ values ranging from 0.88 to 0.98 . The lowest slope among cultivars was $11.6 \pm 0.46 \mathrm{mg} \mathrm{H}_{2} \mathrm{O} \mathrm{m}^{-2} \mathrm{~s}^{-1} \mathrm{kPa}^{-1}$ for AT 3085 and the highest was $30.8 \pm 0.97 \mathrm{mg} \mathrm{H}_{2} \mathrm{O} \mathrm{m}^{-2} \mathrm{~s}^{-1} \mathrm{kPa}^{-1}$ for $\mathrm{C}$ 76-16. The linear slope of York in the LT experiment of $26.3 \pm 1.15 \mathrm{mg} \mathrm{H}_{2} \mathrm{O} \mathrm{m}^{-2} \mathrm{~s}^{-1} \mathrm{kPa}^{-1}$ was comparable to its slope obtained in the HT experiment $(22.3 \pm 0.92 \mathrm{mg}$ $\left.\mathrm{H}_{2} \mathrm{O} \mathrm{m}^{-2} \mathrm{~s}^{-1} \mathrm{kPa}^{-1}\right)$.

3.2. Transpiration Response to Soil Drying. The commonly observed initial plateau in transpiration response followed by a linear decrease with further soil drying was observed for all peanut cultivars in these experiments. The FTSW threshold for the decline in transpiration rate with drying soil was not significantly different among cultivars in either experiment (Table 4). Also, the FTSW threshold values for the two experiments were similar. The values in WD1 experiment ranged from 0.43 to 0.47 with an average of $0.45 \pm 0.004$ and in WD2 experiment from 0.40 to 0.44 with an average of 0.42 \pm 0.003 .

\section{Discussion}

Unless transpiration is restricted by stomata conductance, plant transpiration is anticipated to increase linearly with increases in the atmospheric vapor pressure deficit [3]. This response was observed for all nine of these commercial cultivars when tested in the LT experiment. However, in the HT experiment the uniformly linear increase in transpiration with VPD was not observed for eight of the nine tested commercial cultivars (Table 2). Only York showed a consistent response between the two experiments with the same linear response over the entire VPD range in both experiments. The results of the experiments reported by Jyostna Devi et al. [9] at $32^{\circ} \mathrm{C}$ for seventeen genotypes from India showed that nine genotypes exhibited a breakpoint while the remaining eight had a linear response over the whole range of VPD.

The marked difference in response to VPD for eight commercial cultivars in this study between the two experiments may be a crucial result of this study. The major environmental difference between the two experiments was the ambient temperature to which the plants were exposed (Table 2). The average temperature during the measurement of the VPD response in $\mathrm{HT}$ experiment $\left(32.0^{\circ} \mathrm{C}\right)$ was nearly $8^{\circ} \mathrm{C}$ greater than the average temperature in LT experiment $\left(24.2^{\circ} \mathrm{C}\right)$. An obvious hypothesis is that temperature acclimation occurred 


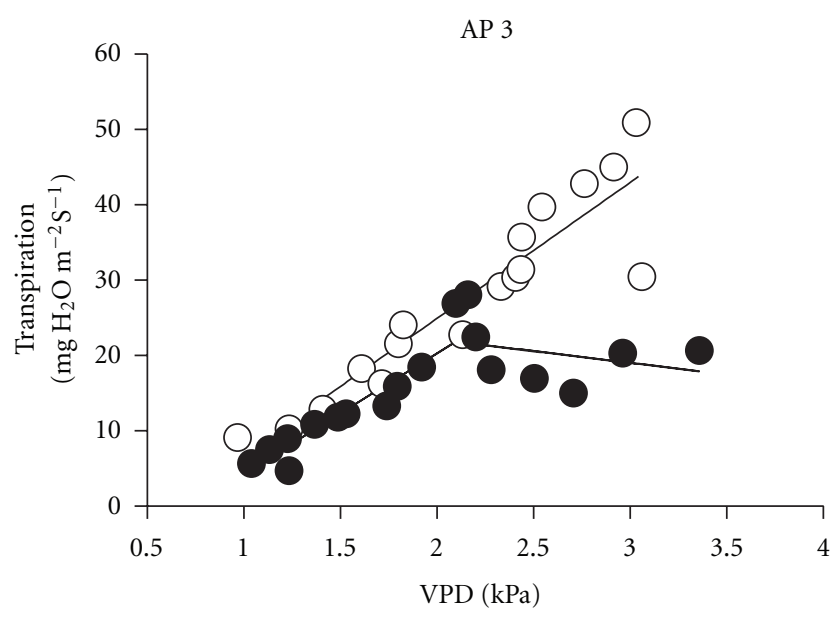

HT experiment

LT experiment

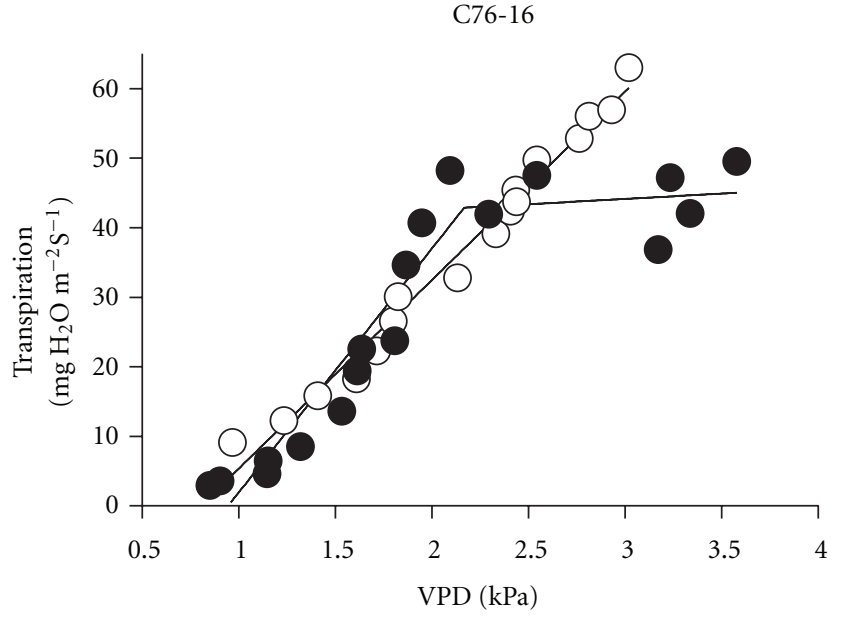

HT experiment

LT experiment

FIgure 1: Transpiration rate versus vapor pressure deficit (VPD) for cultivars AP3 and C 76-16 in High Temperature (HT) and Low Temperature (LT) experiments.

TABLE 2: Linear regression analysis of response to vapor pressure deficit based on the results from the High Temperature experiment. The number of data for each cultivar is listed in the column labeled $n$ and the data are followed by the standard error of the mean. For those cultivars represented by the two-segment regression, slope 1 is for the regression segment below the breakpoint and slope 2 is for the regression above the breakpoint. Break point values followed by the same letter are not significantly different based on their confidence limits.

\begin{tabular}{|c|c|c|c|c|c|c|c|}
\hline \multicolumn{8}{|c|}{ High temperature experiment } \\
\hline Genotype & $n$ & Slope $1 \pm$ S.E. & Break point $\left(X_{0}\right) \pm$ S.E. & Confidence limit of $X_{0}$ & Slope $2 \pm$ S.E. & $X$-intercept & $R^{2}$ \\
\hline AT 3085 & 18 & $21.5 \pm 6.41$ & $1.81 \pm 0.23 \mathrm{a}$ & 1.41 to 1.94 & $3.32 \pm 3.55$ & 0.79 & 0.71 \\
\hline C 99R & 18 & $22.8 \pm 2.63$ & $1.94 \pm 0.11 \mathrm{a}$ & 1.71 to 2.17 & $3.63 \pm 1.87$ & 0.88 & 0.94 \\
\hline GA 06G & 18 & $21.0 \pm 5.70$ & $2.03 \pm 0.12 \mathrm{ab}$ & 1.58 to 2.48 & $-2.90 \pm 6.89$ & 0.92 & 0.61 \\
\hline Tifrunner & 18 & $31.5 \pm 5.30$ & $2.10 \pm 0.08 b$ & 1.95 to 2.26 & $-10.10 \pm 3.22$ & 0.92 & 0.80 \\
\hline AP 3 & 18 & $15.8 \pm 2.99$ & $2.10 \pm 0.14 \mathrm{ab}$ & 1.78 to 2.41 & $-3.19 \pm 3.00$ & 0.72 & 0.81 \\
\hline C 76-16 & 18 & $35.1 \pm 3.97$ & $2.17 \pm 0.16 \mathrm{ab}$ & 1.80 to 2.53 & $1.53 \pm 4.87$ & 0.94 & 0.92 \\
\hline GA 04S & 17 & $16.0 \pm 2.39$ & $2.17 \pm 0.19 \mathrm{ab}$ & 1.75 to 2.59 & $-1.27 \pm 3.82$ & 0.64 & 0.86 \\
\hline \multirow[t]{2}{*}{ FL 07} & 18 & $22.8 \pm 3.53$ & $2.25 \pm 0.13 b$ & 1.96 to 2.54 & $-6.19 \pm 3.40$ & 0.87 & 0.89 \\
\hline & & Slope & $Y$-intercept & $X$-intercept & $R^{2}$ & & \\
\hline York & 16 & $22.3 \pm 0.92$ & $-20.0 \pm 2.25$ & 0.89 & 0.97 & & \\
\hline
\end{tabular}

in eight of the cultivars so that under the hotter temperatures water loss was restricted at high VPD but under cooler temperatures no such restriction existed.

A hypothesis to explain the temperature sensitivity could be the involvement of aquaporins. Aquaporins are critical for high rates of water transport between cells [25-28]. Limited aquaporin populations could restrict water flow in the plant resulting in an inability to sustain high transpiration rates at high VPD. Ionenko et al. [29] in their recent study with maize showed that water transport through aquaporins was temperature sensitive. They found that the maximum water flow through water channels occurred in the optimum temperature region of 20 to $25^{\circ} \mathrm{C}$ and decreased or suppressed water conductance in the higher temperature range of 30 to $35^{\circ} \mathrm{C}$. If the results with maize are applicable to peanut, the decreased hydraulic conductance at the higher temperature means that these plants could not transport the high water flow required at high VPD. As a result, stomata would be obligated to limit transpiration rate and result in the expression of the breakpoint in the HT experiment, but not in the LT experiment.

Possible temperature acclimation in the transpiration response observed here could be an important asset for these commercial cultivars. These cultivars with the temperature acclimation have the capability to have restricted transpiration rate under high VPD when temperatures are high. These conditions would exist when the demand for water is high and potential water loss from the plants is high. The cultivars acclimating to a high temperature with a BP in the VPD response appeared to have the capability to switch to a 
TABLE 3: Linear regression analysis of response to vapor pressure deficit based on the results from the Low Temperature experiment. The number of data for each cultivar is listed in the column labeled $n$ and the data are followed by the standard error of the mean.

\begin{tabular}{lccccc}
\hline \multicolumn{7}{c}{ Low temperature experiment } \\
Genotype & $n$ & Slope \pm S.E. & $Y$-intercept & $X$-intercept & $R^{2}$ \\
\hline AT 3085 & 18 & $11.6 \pm 0.46$ & $-7.73 \pm 0.96$ & 0.66 & 0.98 \\
C 99R & 18 & $12.9 \pm 1.30$ & $-6.48 \pm 3.15$ & 0.49 & 0.93 \\
GA 06G & 17 & $14.7 \pm 1.89$ & $-14.3 \pm 4.54$ & 0.97 & 0.80 \\
Tifrunner & 18 & $24.9 \pm 2.04$ & $-19.7 \pm 4.49$ & 0.79 & 0.92 \\
AP 3 & 17 & $18.1 \pm 1.93$ & $-11.1 \pm 4.32$ & 0.62 & 0.85 \\
C 76-16 & 18 & $27.1 \pm 0.96$ & $-21.7 \pm 2.13$ & 0.80 & 0.99 \\
GA 04S & 18 & $15.4 \pm 2.17$ & $-14.7 \pm 5.31$ & 0.95 & 0.80 \\
FL 07 & 18 & $18.7 \pm 0.85$ & $-16.7 \pm 1.78$ & 0.89 & 0.98 \\
York & 16 & $26.3 \pm 1.15$ & $-27.0 \pm 2.67$ & 1.02 & 0.97 \\
\hline
\end{tabular}

TABLE 4: Results from the two deficit experiments (WD1 and WD2) showing the FTSW-threshold for the decline in transpiration rate. Values followed with the same letter are not statistically different on LSD (Least Significant Difference) values calculated using Tukeys method $(P<0.05)$. The notation NS means nonsignificant.

\begin{tabular}{lcc}
\hline Genotype & WD1 & WD2 \\
FTSW Threshold & FTSW Threshold \\
\hline AP 3 & $0.46 \mathrm{a}$ & $0.42 \mathrm{a}$ \\
AT 3085 & $0.46 \mathrm{a}$ & $0.43 \mathrm{a}$ \\
C 76-16 & $0.46 \mathrm{a}$ & $0.41 \mathrm{a}$ \\
C 99R & $0.47 \mathrm{a}$ & $0.42 \mathrm{a}$ \\
FL 07 & $0.44 \mathrm{a}$ & $0.43 \mathrm{a}$ \\
GA 04S & $0.46 \mathrm{a}$ & $0.40 \mathrm{a}$ \\
GA 06G & $0.46 \mathrm{a}$ & $0.44 \mathrm{a}$ \\
Tifrunner & $0.45 \mathrm{a}$ & $0.42 \mathrm{a}$ \\
York & $0.43 \mathrm{a}$ & $0.42 \mathrm{a}$ \\
L.S.D. & $\mathbf{0 . 0 6}$ & $\mathbf{0 . 0 3}$ \\
P & $\mathbf{N S}$ & $\mathbf{N S}$ \\
\hline
\end{tabular}

water-conserving mode and decrease the risk of water deficits developing in the soil. Under cooler temperatures, stomata remained open under all VPD conditions so that $\mathrm{CO}_{2}$ assimilation is not restricted under these conditions. Clearly, more research is required to explore the acclimation possibilities in these cultivars and to understand the consequences on crop water use and yield.

The general transpiration response to FTSW was similar to previous reports and was similar among these nine commercial cultivars. The threshold for the decline in transpiration rate was observed at a threshold FTSW of slightly greater than 0.4 for all cultivars in both experiments (Table 4). These results were similar to the results observed with the other species in which threshold value was around 0.4 [11-14, 17-22]. Previously, Jyostna Devi et al. [23] found a large variation among peanut genotypes from India in their threshold for transpiration rate decline. The lack of any variation among the US commercial cultivars indicates that such a trait was not present in parent lines of these cultivars, or progeny selection never favored identification of diversity in the expression of this trait.

Overall, these results do not highlight any major differences among the nine US commercial peanut cultivars in their response to either VPD or soil drying. The one exception was that York sustained a continuing increase in transpiration with increasing VPD in the HT experiment. This result indicates that York may have an aquaporin population somewhat different from the other eight cultivars. The general uniformity of results for these two drought traits among the commercial cultivars indicates that a possibility exists for developing differences in the expression of the two putative traits for enhanced peanut drought tolerance. Jyostna Devi et al. $[9,23]$ showed large variation among seventeen genotypes from India indicating that genetic resources exist for such a breeding effort.

\section{References}

[1] I. R. Cowan, "Transport of water in the soil-plant-atmosphere system," Journal of Applied Ecology, vol. 2, pp. 221-239, 1965.

[2] F. Tardieu, J. Zhang, N. Katerji, O. Bethenod, S. Palmer, and W. J. Davies, "Xylem ABA controls the stomatal conductance of fieldgrown maized subjected to soil compaction or soil drying," Plant, Cell and Environment, vol. 15, pp. 193-197, 1992.

[3] T. R. Sinclair and J. M. Bennett, "Water," in Principles of Ecology in Plant Production, T. R. Sinclair and F. P. Gardner, Eds., pp. 103-120, CAB International, 1998.

[4] A. L. Fletcher, T. R. Sinclair, and L. H. Allen Jr., "Transpiration responses to vapor pressure deficit in well watered "slowwilting" and commercial soybean," Environmental and Experimental Botany, vol. 61, no. 2, pp. 145-151, 2007.

[5] T. R. Sinclair, M. A. Zwieniecki, and N. M. Holbrook, "Low leaf hydraulic conductance associated with drought tolerance in soybean," Physiologia Plantarum, vol. 132, no. 4, pp. 446451, 2008.

[6] W. Sadok and T. R. Sinclair, "Genetic variability of transpiration response to vapor pressure deficit among soybean cultivars," Crop Science, vol. 49, no. 3, pp. 955-960, 2009.

[7] M. Gholipoor, P. V. V. Prasad, R. N. Mutava, and T. R. Sinclair, "Genetic variability of transpiration response to vapor pressure deficit among sorghum genotypes," Field Crops Research, vol. 119, no. 1, pp. 85-90, 2010.

[8] J. Kholova, C. T. Hash, P. L. Kumar, R. S. Yadav, M. Koová, and V. Vadez, "Terminal drought-tolerant pearl millet [Pennisetum glaucum (L.) R. Br.] have high leaf ABA and limit transpiration at high vapour pressure deficit," Journal of Experimental Botany, vol. 61, no. 5, pp. 1431-1440, 2010.

[9] M. Jyostna Devi, T. R. Sinclair, and V. Vadez, "Genotypic variation in peanut for transpiration response to vapor pressure deficit," Crop Science, vol. 50, no. 1, pp. 191-196, 2010.

[10] J. T. Ritchie, "Soil water availability," Plant and Soil, vol. 58, no. 1-3, pp. 327-338, 1981.

[11] T. R. Sinclair and M. M. Ludlow, "Influence of soil water supply on the plant water balance of four tropical grain legumes," Australian Journal of Plant Physiology, vol. 13, no. 3, pp. 329-341, 1986.

[12] J. D. Ray and T. R. Sinclair, "Stomatal closure of maize hybrids in response to drying soil," Crop Science, vol. 37, no. 3, pp. 803807, 1997. 
[13] J. D. Ray and T. R. Sinclair, "The effect of pot size on growth and transpiration of maize and soybean during water deficit stress," Journal of Experimental Botany, vol. 49, no. 325, pp. 1381-1386, 1998.

[14] R. Serraj, T. R. Sinclair, and L. C. Purcell, "Symbiotic $\mathrm{N}_{2}$ fixation response to drought," Journal of Experimental Botany, vol. 50, no. 331, pp. 143-155, 1999.

[15] P. Bhatnagar-Mathur, M. J. Devi, D. S. Reddy et al., "Stressinducible expression of at DREB1A in transgenic peanut (Arachis hypogaea L.) increases transpiration efficiency under water-limiting conditions," Plant Cell Reports, vol. 26, no. 12, pp. 2071-2082, 2007.

[16] P. Bhatnagar-Mathur, V. Vadez, M. Jyostna Devi, M. Lavanya, G. Vani, and K. K. Sharma, "Genetic engineering of chickpea (Cicer arietinum L.) with the P5CSF129A gene for osmoregulation with implications on drought tolerance," Molecular Breeding, vol. 23, no. 4, pp. 591-606, 2009.

[17] W. S. Meyer and G. C. Green, "Plant indicators of wheat and soybean crop water stress," Irrigation Science, vol. 2, no. 3, pp. 167-176, 1981.

[18] T. Gollan, J. B. Passioura, and R. Munns, "Soil water status affects the stomatal conductance of fully turgid wheat and sunflower leaves," Australian Journal of Plant Physiology, vol. 13, pp. 459-464, 1986.

[19] W. D. Rosenthal, G. F. Arkin, and W. R. Jordan, "Water deficit effects on transpiration and leaf growth," Agronomy Journal, vol. 79, pp. 1019-1026, 1987.

[20] B. I. L. Kuppers, M. Kuppers, and E. D. Schulze, "Soil drying and its effect on leaf conductance and $\mathrm{CO}_{2}$ assimilation of Vigna unguiculata (L.) Walp I. The response to climatic factors and to the rate of soil drying in young plants," Oecologia, vol. 75, no. 1, pp. 99-104, 1988.

[21] R. Weisz, J. Kaminski, and Z. Smilowitz, "Water deficit effects on potato leaf growth and transpiration: utilizing fraction extractable soil water for comparison with other crops," American Potato Journal, vol. 71, no. 12, pp. 829-840, 1994.

[22] V. O. Sadras and S. P. Milroy, "Soil-water thresholds for the responses of leaf expansion and gas exchange: a review," Field Crops Research, vol. 47, no. 2-3, pp. 253-266, 1996.

[23] M. Jyostna Devi, T. R. Sinclair, V. Vadez, and L. Krishnamurthy, "Peanut genotypic variation in transpiration efficiency and decreased transpiration during progressive soil drying," Field Crops Research, vol. 114, no. 2, pp. 280-285, 2009.

[24] "Inoculation methods for field experimenters and farmers," in Nitrogen Fixation in Legumes, J. Brockwell, Ed., pp. 211-221, 1982.

[25] T. Henzler and E. Steudle, "Reversible closing of water channels in Chara internodes provides evidence for a composite transport model of the plasma membrane," Journal of Experimental Botany, vol. 46, no. 283, pp. 199-209, 1995.

[26] M. Tazawa, E. Ohkuma, M. Shibasaka, and S. Nakashima, "Mercurial-sensitive water transport in barley roots," Journal of Plant Research, vol. 110, no. 1100, pp. 435-442, 1997.

[27] W. H. Zhang and S. D. Tyerman, "Inhibition of water channels by $\mathrm{HgCl}_{2}$ in intact wheat root cells," Plant Physiology, vol. 120, no. 3, pp. 849-857, 1999.

[28] C. Maurel and M. J. Chrispeels, "Aquaporins. A molecular entry into plant water relations," Plant Physiology, vol. 125, no. 1, pp. 135-138, 2001.

[29] I. F. Ionenko, A. V. Anisimov, and N. R. Dautova, "Effect of temperature on water transport through aquaporins," Biologia Plantarum, vol. 54, no. 3, pp. 488-494, 2010. 


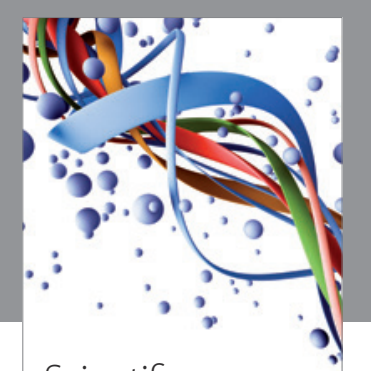

Scientifica
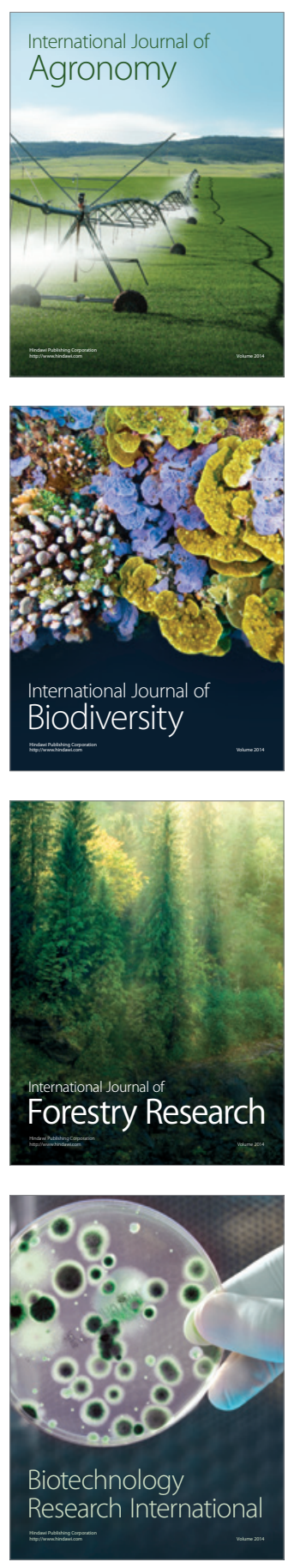
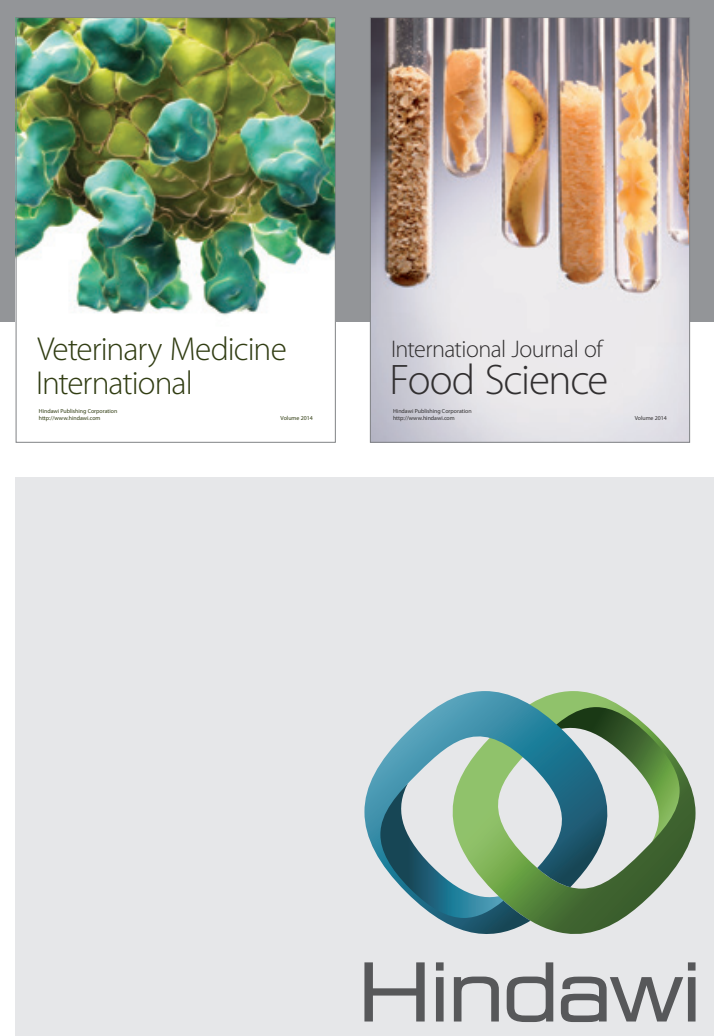

Submit your manuscripts at

http://www.hindawi.com
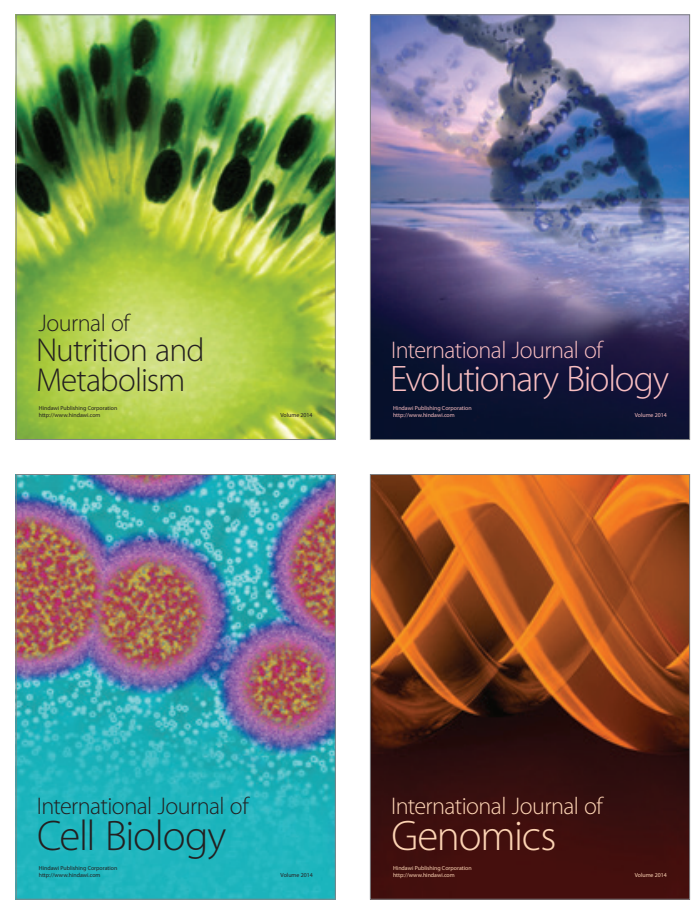
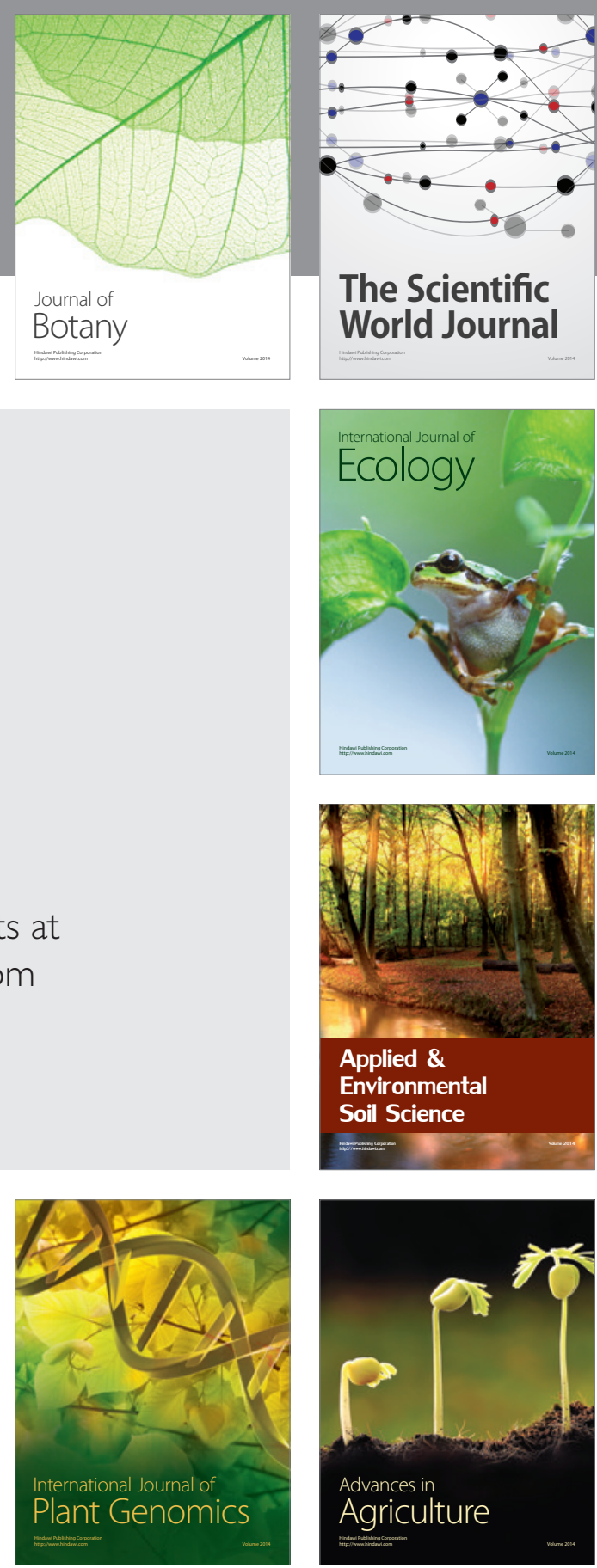

The Scientific World Journal
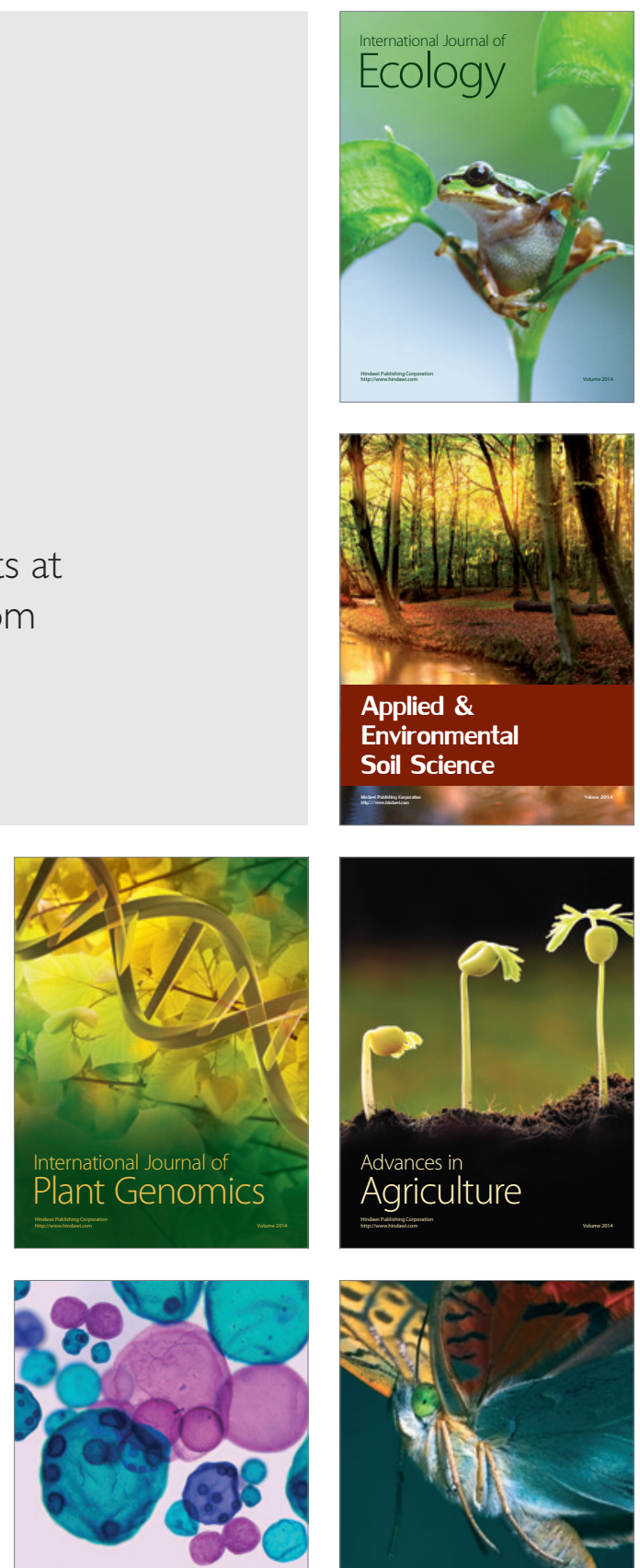

International Journal of Microbiology

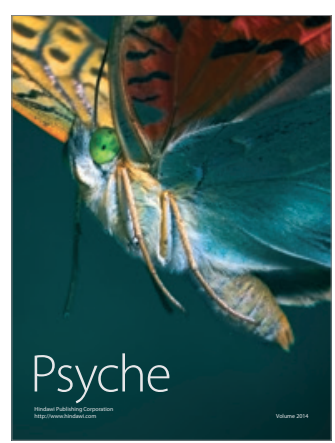

